\title{
Cross Cultural Differences in Cultural Intelligence and Quality of Life among Adults
}

\author{
Nayanika Singh ${ }^{1}$, Prathma Sharma ${ }^{2}$, Mahasweta Bose $^{3}$
}

\section{ABSTRACT:}

Cultural Intelligence refers to an individual's ability to successfully adapt oneself to culturally diverse environments', the capacity to act and behave appropriately, according to one's cultural environment. It refers to an individual's capability to function effectively across cultures. To have high levels of cultural intelligence may be based on various aspects of intelligence like social and emotional intelligence (Earley and Ang, 2003). The idea of cultural intelligence has emerged in the last few years, owing to the process of globalization which has turned the world into a global village. There are mainly four factors affecting cultural intelligence: Motivational which refers to an individual's drive and interest to adapt one to a cross-cultural environment; Cognitive which id the knowledge dimension of CQ; Metacognitive which includes awareness, planning and checking and Behavioral component which refers to the verbal, non verbal speech acts. The term quality of life (QOL) references the general well-being of individuals and societies. The term is used in a wide range of contexts, including the fields of international development, healthcare, and politics. This study attempts to study the effect of gender and culture on both the cultural intelligence and the quality of life of adults. The sample consisted of 120 adults aged between 18-40 years, with 60 males and 60 females belonging to Himachali and Punjabi cultures. The Cultural Intelligence scale developed by Soon et al (2007) was used to measure the cultural intelligence of the adults. This scale measures the 4 components of CQmotivational, cognitive, meta-cognitive and behavioral. Quality of life was measured by using the Quality Of Life Scale (Burakhardt, Carol S., 1993). This questionnaire is a self - report inventory that consists of 16 items, pertaining to the various aspects of quality of life i.e. emotional, cognitive and behavioral. The hypothesis stated that males of both the cultures (Himachali and Punjabi) will have a higher cultural intelligence than females of both the cultures, there will be no significant differences in the quality of life of males and females. Punjabi adults will have a better quality of life and higher cultural intelligence than Himachali adults. Findings of the study indicated a) that male adults were found to be higher than their female counter parts on cultural intelligence, b) no significant differences were found between male and female adults on QOL, c) Punjabis were found to higher on both cultural intelligence and QOL than their Himachali counter parts; significantly proving the stated hypotheses. This is one of the first of its kind study conducted in the Indian set-up and further research is needed to substantiate the same.

Keywords: Cross Cultural, Cultural Intelligence, Quality Life, Adults

${ }^{1}$ Assistant Professor, Department of Psychology, DAV College, Sector-10, Chandigarh,

${ }^{2}$ Graduate students, Dept. Of Psychology, DAV College, sector- 10, Chandigarh

${ }^{3}$ Graduate students, Dept. Of Psychology, DAV College, sector- 10, Chandigarh

(C) 2015 I N Singh, P Sharma, M Bose; licensee IJIP. This is an Open Access Research distributed under the terms of the Creative Commons Attribution License (http://creativecommons.org/licenses/by/2.0), which permits unrestricted use, distribution, and reproduction in any Medium, provided the original work is properly cited. 
Human beings are integral parts of the society and its culture. "Culture" is one of the most widely used concepts in social sciences. It has been defines in a myriad of ways. In lay man's terms, "culture is the way of life which members of a society share and follow." It is the way of acting, the body of tradition, ritual and the beliefs which people have learned as members of a society. As opined by Geert Hofstede, culture is "the collective programming of mind which distinguishes one group or category of people from another" (Lane, Di Stefano \& Maznevski 2006, pI.24). ${ }^{1}$ Trompenaars and Hampden-Turner define culture as "a shared system of meanings." (Trompenaars \& Hampden-Turner, 1997, p. 13) ${ }^{2}$ However, Hofstede (1997) states that culture is a structure of collectively held values and collective mental programming which separate or distinguish various groups of people from others (Hofstede G., 1997). ${ }^{3}$ Each individual has several layers of mental programming that gradually build as they grow and learn (Hofstede G. 1980). The deepest, fundamental layers are created at a young age, and then as one progresses through education, technical training, professional training, and life in general, other layers of their mental programming are created. The layers formed in later years have more to do with actions, ways of doing things, and ethics rather than various types of training (Hofstede G.1980). The more an individual learns through experience as they get older, the greater their ability is to react properly in various situations, cultural and otherwise. This is the reason why two individuals although belonging to the same culture, behave differently in similar situations.

\section{Cultural Intelligence}

Intelligence is defined as "A term referring to a variety of mental capabilities, including the ability to reason, plan, solve problems, think abstractly, comprehend complex ideas, learn quickly, and learn from experience," by Thomson Gale (Gale, 1998).Earlier, intelligence was seen only in terms of academic aptitude and but now intelligence is also viewed as aptitude that extends beyond an academic setting (Sternberg \& Detterman, 1986). The concept of multiple intelligence has gained ground in the present day world. Different types of intelligences have been coined by various researches. Practical intelligence is defined by Sternberg (2000) as the "ability that individuals use to find the best fit between themselves and the demands of the environment" (Sternberg, et al., 2000). Emotional intelligence deals with the ability to recognize and deal with personal emotions, without any consideration for varying cultural environments (Ang, et al., 2007).Robert J. Sternberg believes that there are many reasons why people identified as intelligent by academic standards cannot succeed in everyday life, such as lack of motivation or lack of perseverance (Sternberg, 1986).

The idea of cultural intelligence has emerged in the last few years, owing to the process of globalization which has turned the world into a global village. To be culturally intelligent (from now on referred to as CQ) means to "be skilled and flexible about understanding a culture, learning more about it with your ongoing interactions with it, and gradually reshaping your thinking to be more sympathetic to the culture and your behavior to be more skilled and appropriate when interacting with others from the culture" (Thomas, Inkson 2004, p.14). Cultural Intelligence refers to an individual's ability to successfully adapt oneself to culturally diverse 
environments, the capacity to act and behave appropriately, according to one's cultural environment. To have high levels of cultural intelligence may be based on various aspects of intelligence like social and emotional intelligence (Earley and Ang, 2003). To get a better understanding of the topic of cultural intelligence (to now on be referred to as CQ) we must try to differentiate between the concepts of emic and etic constructs. Emic constructs are referred to exist uniquely in one culture, thus receiving it's meaning by its context, while etic constructs are universal and exist across cultures (Earley, Murnieks \& Masakowski 2007). Murdock (1945) created a list of seventy cultural universals that included variables such as: food taboos, folklore, etc. Berry (1997), however, argued that there are variables that not as universal as they appear. The author named those variables "imposed-etics" that are usually represented in a number of cultures but not in all. Individuals high on cultural intelligence will be able to blend easily across various new cultures and effectively interact in an intercultural environment even when most of verbal and non-verbal cues that have worked for them in the past may be largely useless to them now and when other people's behavior and actions may even seem bizarre alien at times.

\section{The Four Factor Model of Cultural Intelligence}

CQ consists of four inter-related yet distinct factors which when enhanced together may result in enhanced CQ, rather than when a single factor is focused upon. The four factors are as follows:

1. Motivation: This factor refers to an individual's drive and interest to adapt one to a crosscultural environment, in the way one interacts and acts towards others members of the culture, to overcome the conflicts, accompanying the process engaging one through intercultural experiences. The individual has to have high energy and drive to persevere and stay motivated to experience new situations head-on. Motivational CQ consists of intrinsic motivation- internal factors that end up motivating us e.g. enjoyment derived from the process, extrinsic motivationexternal factors motivating us to persevere like materialistic benefits associated with the process, and self-efficacy is an individual's belief in oneself to succeed in particular tasks.

2. Cognition: Cognitive CQ refers to the extent an individual has the necessary knowledge on how to behave and act with other members in a cross-cultural environment, and how much helshe understands the norms, values and the particular mannerisms of one's culture and the way it shapes one's thinking. Every culture has its own economic system, religions, social stratification system and particular social institutions and the norms and laws governing them. Thus, an individual must have adequate knowledge of all these related topics and the ability to differentiate between them to have an enhanced level of cognitive CQ.

3. Meta-cognition: Metacognitive CQ refers to an individual's ability to plan and think ahead, to strategize by observing how others behave and trying to understand how others think in crosscultural situations. Metacognitive CQ is enhanced when we put our cultural knowledge to use, to be aware and think about our own thought processes to solve problems or conflicts in such a situation. One's expectations for such a situation must also be compared to what actually occurs. Individuals high on metacognition interacting in cross-cultural situations are able to question 
their cultural assumptions and alter their own cultural knowledge (Thomas, Elron\& Stahl 2008, Ang, and Van Dyne 2008).

4. Behavior: Behavioral CQ refers to an individual's ability to react and act accordingly in a variety of cross-cultural situation, one should also be aware of when to adapt and when not to adapt to a cross-cultural situation so as to ensure maximum effectiveness. The individual should also possess knowledge about verbal and non-verbal actions to make oneself understood in a wide variety of situations.

\section{QUALITY OF LIFE}

Researchers have long since been attempting to construct alternative, on-monetary indices of social and economic well-being in a single statistic, a variety of different factors that ought to influence quality of life, as GDP per person alone cannot measure the broader quality of life in a country (The Economist Intelligence Unit's quality-of-life index,2005). The term quality of life (QOL) references the general well-being of individuals and societies. The term is used in a wide range of contexts, including the fields of international development, healthcare, and politics. Quality of life should not be confused with the concept of standard of living, which is based primarily on income. Instead, standard indicators of the quality of life include not only wealth and employment but also the built environment, physical and mental health, education, recreation and leisure time, and social belonging ( 1993, The Quality of Life, Oxford: Clarendon Press). Also frequently related are concepts such as freedom, human rights, and happiness. However, since happiness is subjective and difficult to measure, other measures are generally given priority. It has also been shown that happiness, as much as it can be measured, does not necessarily increase correspondingly with the comfort that results from increasing income. Quality of life is an important concept in the field of international development, since it allows development to be analyzed on a measure broader than standard of living. Within development theory, however, there are varying ideas concerning what constitutes desirable change for a particular society, and the different ways that quality of life is defined by institutions therefore shapes how these organizations work for its improvement as a whole. As a result, standard of living should not be taken to be a measure of happiness (Richard Layard, 2006). Also sometimes considered related is the concept of human security, though the latter may be considered at a more basic level and for all people. Unlike per capita GDP or standard of living, both of which can be measured in financial terms, it is harder to make objective or long-term measurements of the quality of life experienced by nations or other groups of people. Researchers have begun in recent times to distinguish two aspects of personal well-being: Emotional well-being, in which respondents are asked about the quality of their everyday emotional experiences--the frequency and intensity of their experiences of, for example, joy, stress, sadness, anger, and affection-- and life evaluation, in which respondents are asked to think about their life in general and evaluate it against a scale. Such and other systems and scales of measurement have been in use for some time. Research has attempted to examine the relationship between quality of life and productivity (Federal Reserve Bank of Kansas City, The Increasing Importance of Quality of Life, 2008). 
Perhaps the most commonly used international measure of development is the Human Development Index (HDI), which combines measures of life expectancy, education, and standard of living, in an attempt to quantify the options available to individuals within a given society. The HDI is used by the United Nations Development Programme in their Human Development Report (Undp.org. 2013).

\section{DETERMINANTS OF QUALITY OF LIFE:}

The 9 quality-of-life factors and the indicators used to represent these factors are; 1)Material G.D.P. well-being - G.D.P. per person

2)Health - Life expectancy at birth, years

3)Political stability and security - Political stability and security ratings

4)Family life

5)Community life

6)Climate and geography

7)Political freedom

8)Job security

9)Gender equality

\section{REVIEW OF LITERATURE}

Yordanova K. (2011) ties both subjects and analyzes the effect of managerial cultural intelligence on multicultural team performance. Data for the study was collected by a theoretical and a quantitative empirical investigation. The theoretical investigation includes conceptualization, theories and frameworks towards both cultural intelligence and multicultural team work. The empirical investigation was conducted with the use of a questionnaire. The questionnaire results were analyzed in order to reach a conclusion.

Van Dyne, L., Ang, S., \& Livermore, D., (2010) in their article "Cultural intelligence: A pathway for leading in a rapidly globalizing world" have discussed the main sub categories of cultural intelligence viz motivational, cognitive, metacognitive and behavioral cultural intelligence. They have also enumerated the steps to enhance one's overall cultural intelligence with the help of case studies.

Thomas, David C. and Kerr Inkson (2008), in their titled "Cultural Intelligence: people skills for global business" based on their studies discussed the importance of cross-cultural people skills in the organisational context where managing people effectively is the key to organizational effectiveness, and the people in organizations are increasingly multicultural. The book emphasized on the fact that, acquiring cultural intelligence assists not only to survive without difficulty or embarrassment in the new global, multicultural business environment, but to pursue your goals in this environment with the confidence needed for success. 
Esther Herrmann, Josep Call, María Victoria Hernàndez-Lloreda, Brian Hare Michael Tomasello through their collaborative study argued that cultural intelligence was mainly due to a speciesspecific set of social-cognitive skills, emerging early in ontogeny, for participating and exchanging knowledge in cultural groups. They tested this hypothesis by giving a comprehensive battery of cognitive tests to large numbers of two of humans' closest primate relatives, chimpanzees and orang-utans, as well as to 2.5-year-old human children before literacy and schooling. Supporting the cultural intelligence hypothesis and contradicting the hypothesis that humans simply have more "general intelligence," they found that the children and chimpanzees had very similar cognitive skills for dealing with the physical world but that the children had more sophisticated cognitive skills than either of the ape species for dealing with the social world.

Ng, K.Y., Van Dyne, L., \& Ang, S. (2012) in their paper on "Cultural intelligence: A review, reflections, and recommendations for future research." Emphasized the importance of cultural intelligence in the fast globalizing world. They stressed on the measurement of cultural intelligence using various techniques and provide arenas for further research.

Sprangers and Schwartz (1999), cocluded that patients confronted with a life-threatening or chronic disease are faced with the necessity to accommodate to their illness. An important mediator of this adaptation process is 'response shift' which involves changing internal standards, values and the conceptualization of quality of life (QOL).Integrating response shift into QOL research would allow a better understanding of how QOL is affected by changes in health status and would direct the development of reliable and valid measures for assessing changes in QOL.

Rahman, Mittelhammer and Wandschneider, (2005) attempted to provide a comprehensive analysis of interrelationships among the determinants of the quality of life (QOL). They showed that various measures of well-being are highly sensitive to domains of QOL that are considered in the construction of comparative indices, and how measurable well-being indicators are aggregated and weighted to arrive at composite measures of QOL.

Hawthorne, Korn and Richardson (2007) provided Australian health-care related quality of life (HRQol) population norms, based on utility scores from Assessment Quality of Life (AQol) measure, a participant-reported outcomes experiment.

The above review of literature indicates a substantial gap of studying the accumulative effect of both Cultural Intelligence \& Quality Of Life among the older adults and younger adults, making this study a novel one and the first of its kind. 
Cross Cultural Differences in Cultural Intelligence and Quality of Life among Adults

\section{OBJECTIVES:}

(a) To study the effect of gender on the cultural intelligence of Himachalis and Punjabis aged 18-40 years..

(b) To study the effect of gender on the quality of life of Himachalis and Punjabis aged 18-40 years.

(c) To study the effect of culture on the cultural intelligence of Himachalis and Punjabis aged 18-40 years..

(d) To study the effect of culture on the quality of life of Himachalis and Punjabis aged 18-40 years.

\section{HYPOTHESES:}

(a) Males aged 18-40 years will have a higher level of cultural intelligence than their female counterparts.

(b) There will be no significant differences in levels of quality of life of males and females, aged 18-40 years.

(c) Himachali adults will have a lower level of cultural intelligence than Punjabi adults.

(d) Punjabi adults will have a higher level of quality of life than Himachali adults.

\section{METHODOLOGY}

Sample: The sample for the present study consisted of 120 adults, 60 males and 60 females in the age group of 18-40 from Chandigarh (Punjab) and Shimla (Himachal).

\section{Tools:}

\section{The Cultural Intelligence Scale}

The CQS was developed by Soon (2007) and her colleagues in order to create a framework that can measure CQ. It was aimed at testing the dimensions of metacognition, cognition, motivation and behaviour with four to six items. Each item was created towards one idea and was formulated in a clear and understandable way. Initially, the scale consisted of a forty item questionnaire that was measured on a seven point Likert scale where $1=$ strongly disagree and $7=$ strongly agree. After conducting several specification researches twenty out of forty items were deleted due to high residuals, small standard deviations, etc. Therefore, the original CQS consists of twenty questionnaire items which are distributed as following: four items for metacognitive CQ; six items for cognitive CQ; five items for motivational CQ; and five items for behavioral CQ. In order to conclude on the validity and generalizability of the scale, it was tested across samples, across time and across countries. (Ang, Van Dyne 2008, Ang et al. 2007).

\section{Quality of Life Questionnaire}

Quality Of Life Scale (Burakhardt, Carol S., 1993). This questionnaire is a self - report inventory that consists of 16 items, pertaining to the various aspects of quality of life i.e. emotional, 
cognitive and behavioral. The items are related to the level of satisfaction with the various things in life like inter- personal relationships, materialistic things, career and the general contentment with life. Each item is provided with seven response alternatives (Delighted, Pleased, Mostly Satisfied, Mixed, Mostly Dissatisfied, Unhappy, and Terrible) and the subject has to circle the option that applies for him / her. The scores for each item are added to obtain the final score for QOL.

\section{Statistical Analysis:}

The responses to various tests were scored according to the directions set in the manuals of the test and with the help of scoring keys. Means were computed for the different sets of data and independent sample t-test was applied to test the significance of mean difference between male and female adults from both Punjabi and Himachali cultures.

\section{RESULTS AND DISCUSSION:}

The present study attempted to assess the impact of gender and culture on the cultural intelligence and quality of life of adults aged between 18-40 years from Punjabi and Himachali cultures, for which the data was divided into two categories, one of males and females and the other of Punjabi culture and Himachali culture. The independent sample t-test was applied for the purpose of statistical interpretation to test the significance of difference between these four means. Results and discussion for the present study are as follows:

\section{The following table (Table 1) indicates the effect of gender on Cultural Intelligence among Himachalis and Punjabis}

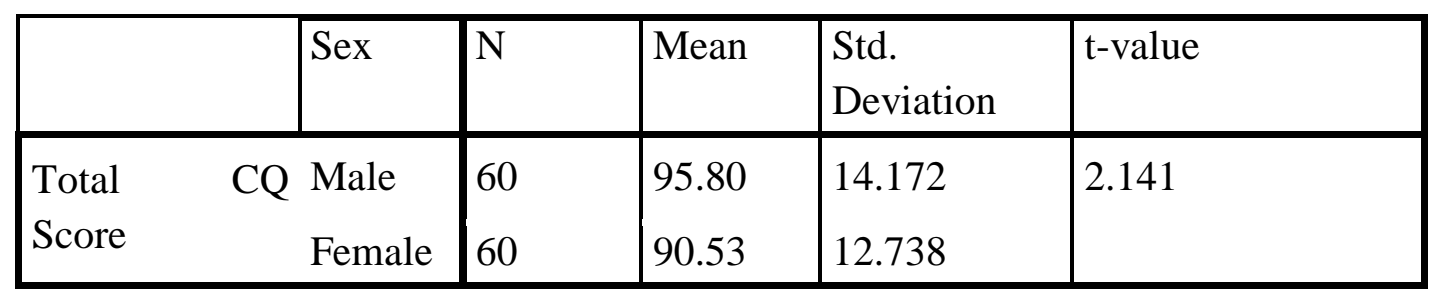

Significant at $(.05=1.98)(\mathrm{df}=119)$

Results summarized in Table 1 indicate the effect of gender on cultural intelligence among Himachalis and Punjabis, aged 18-40 years. The mean value for males was found to be 95.80 while for the females it was found to be 90.53 . The $t$-value was found to be 2.141 , which was found to be significant at the level of .05 , indicating that gender has a significant effect on the cultural intelligence of both males and females among Himachalis and Punjabis. Therefore, our first hypothesis (i.e. Males aged 18-40 years will have a higher level of cultural intelligence than the females, aged 18-40 years) stands accepted. 
The following table (Table 2) indicates the effect of gender on Quality of Life among Himachalis and Punjabis

\begin{tabular}{|c|c|c|c|c|c|}
\hline & Sex & $\mathrm{N}$ & Mean & $\begin{array}{l}\text { Std. } \\
\text { Deviation }\end{array}$ & $\mathrm{t}$-value \\
\hline $\begin{array}{l}\text { Quality Of life } \\
\text { score }\end{array}$ & $\begin{array}{l}\text { Male } \\
\text { Female }\end{array}$ & $\begin{array}{l}60 \\
60\end{array}$ & $\begin{array}{l}87.83 \\
87.83\end{array}$ & $\begin{array}{l}12.577 \\
11.380\end{array}$ & 0.00 \\
\hline
\end{tabular}

No significant differences

Results summarized in Table 2 indicate the effect of gender on quality of life among Himachalis and Punjabis, aged 18-40 years. The mean value for both males and females were found to be 87.83 , while the t-value came out to 0.00 , thus indicating that there are no significant differences at the level of .05 and no significant effect of gender on the quality of life among males and females among Himachalis and Punjabis. Therefore, our second hypothesis (i.e. Males and females, aged 18-40 years will have no significant differences in their levels of quality of life) stands accepted.

The following table (Table 3) indicates the effect of Culture on Cultural Intelligence among Himachalis and Punjabis

\begin{tabular}{|l|l|l|l|l|l|}
\hline & Culture & $\mathrm{N}$ & Mean & Std. Deviation & t-value \\
\hline \multirow{2}{*}{ Total CQ Score Himachali } & 60 & 91.02 & 14.092 & 1.737 \\
& Punjabi & 60 & 95.32 & 13.008 & \\
\hline
\end{tabular}

Not Significant at $(.05=1.98)(\mathrm{df}=119)$

Results summarized in Table 3 indicate the effect of culture on cultural intelligence among Himachalis and Punjabis, aged 18-40 years. The mean value for Himachalis was found to be 91.02, while the mean value for Punjabis was found to be 95.32. The t-value came out to be 1.737 which was found to be not significant at the level of .05 , hence indicating that culture does not have a significant effect on the cultural intelligence of Himachalis and Punjabis.

Therefore our third hypothesis (i.e. Adults aged 18-40 years from Himachali culture will have a lower level of cultural intelligence than Punjabis) stands accepted. 
The following table (Table 4) indicates the effect of Culture on Quality of Life among Himachalis and Punjabis

\begin{tabular}{|lc|l|l|l|l|l|}
\hline & & Culture & $\mathrm{N}$ & Mean & $\begin{array}{l}\text { Std. } \\
\text { Deviation }\end{array}$ & t-value \\
\hline $\begin{array}{l}\text { Quality } \\
\text { score }\end{array}$ & Of life Himachali & 60 & 84.23 & 11.867 & 3.45 \\
& Punjabi & 60 & 91.43 & 10.977 & \\
\hline
\end{tabular}

Significant at $(0.5=1.98)(\mathrm{df}=119)$

Results summarized in Table 4 indicate the effect of culture on the quality of life among Himachalis and Punjabis, aged 18-40 years. The mean value for Himachalis was found to be 84.23, while the mean value for Punjabis was found to be 91.43. The t-value came out to be 3.45, which was found to be significant at the level of .05 , hence indicating that culture has a significant effect on the quality of life among Himachalis and Punjabis. Therefore, our fourth hypothesis (i.e. Adults aged 18-40 years from Himachali culture will have a lower level of quality of life than Punjabis) stands accepted.

The plausible explanations for Punjabis having a higher level of cultural intelligence and quality of life than Himachalis may be because of the fact Punjabis have a much greater access to modern technology, live in much urbanized areas than the Himachalis, have a great number of modern amenities at their disposal like multi speciality hospitals, international schools, high speed internet, more modes of recreations like famous restaurants, malls, international brands, amusement parks, huge chains of supermarkets, bookstores etc. Whereas the Himachalis have to face harsh climatic conditions, scarcity of the above mentioned readily available amenities or resources, which even if available are in far-flung areas, shortage of water and problems of electricity, lack of urbanized centres and modern modes of recreation.

Punjabis in urban areas also tend to be much more open minded in terms of trying out new ideas, opportunities and trying to understand and interacting readily with other cultures than the Himachalis.

The present study is one of its kind in Indian setup. However more research on diverse population and newer variables is needed to substantiate the same.

\section{SUGGESTIONS AND RECOMMENDATIONS:}

The following can be some of the suggestions and recommendations to improve the cultural intelligence and quality of life of the adults:

1) Understand the aspects of your life and experiences that most closely connect with the quality of life desired. Research has been conducted on what correlates most with quality of life: 
- Positive emotions: The moments and extended periods we have of different positive moods, including feelings of happiness, gratitude, closeness, confidence, peacefulness and aweinspired.

- Engagement: Periods of time when we are so engaged with the activity we're working on that we have clarity of focus, time seems less relevant, and we are challenged at a level to which we're attracted. This is frequently associated with 'Eustress', which the positive opposite to distress.

- Relationships: The quality of our relationships with others is very highly correlated with our overall quality of life. The strength of our social support structure or 'Personal Safety Net' is fundamental to our coping skills and resiliency when facing challenges in our lives. Our relationships are also a primary source of many of the other aspects of quality of life, especially positive emotions.

- Meaning: How well our work and other endeavours connect with a "greater purpose" contributes enormously to our self esteem and confidence to continue our efforts. The opposite is a feeling that we are wasting our time on trivial tasks that do not contribute to a greater cause. A sense of meaning is often easier to come by if what we do connects with addressing the needs of a community we care about.

- Accomplishment: A sense of accomplishment is closely tied to how well we feel we are able to complete our "to do" lists

- Health: The quality of our physical well-being, including how much pain we're in, how much mobility we have, and how much we can do physically also affects quality of life. According to Gallup's research on global well being, the quality of our sleep plays a critical role in overall quality of life - if we aren't getting enough good rest, we are far more likely to be emotionally overwhelmed or otherwise less productive.

2) Individuals could try to make themselves more culturally aware by reading up about other cultures, not being afraid to venture out and travel to get immerse themselves in a new culture or even watching various movies from other cultures so as not to come across as completely culturally ignorant.

3) Various cultural awareness campaigns could be taken advantage of when conducted, like the ones conducted by several travel magazines and agencies.

4) Most importantly, to increase one's level of cultural intelligence, an individual must always keep an open mind regarding trying out new ideas or learning new things as it is through one's own experience that he/she can boost one's level of cultural intelligence the most. 


\section{REFERENCES:}

Ang, S. \& Van Dyne, L. 2008, Handbook of cultural intelligence: theory, measurement, and applications, M.E. Sharpe, Armonk, N.Y.

Ang, S., Van Dyne, L. \& Koh, C. 2006, "Personality Correlates of the Four-Factor Model of Cultural Intelligence", Group \& Organization Management, vol. 31, no. 1, pp. 100.

Cappeliez, P. (2008). An explanation of the reminiscence bump in dreams of older adults in terms of life goals and identity. Self and Identity, 7(1), 25-33.

Costa, P.T., Jr. \& McCrae, R.R. (1992). Revised NEO Personality Inventory (NEO-PI-R) and NEO Five-Factor Inventory (NEO-FFI) manual. Odessa, FL: Psychological Assessment Resources.

Earley, C. 2002, "Redefining interactions across cultures and organizations: Moving forward with cultural intelligence", Research in Organizational Behavior, vol. 24, pp. 271-299.

Earley, C. \&Ang, S. 2003, Cultural intelligence: individual interactions across cultures, Stanford University Press, Stanford, Calif.

Gale, T. (1998). Gale Encyclopaedia of Childhood and Adolescence

Graeme Hawthorne, Sam Korn and Jeff Richardson (2007), Population norms for the AQol derived from Australian National Survey of MentalHealth and Wellbeing

Gregory, Derek; Johnston, Ron; Pratt, Geraldine; Watts, Michael; Whatmore, Sarah, eds. (June 2009). "Quality of Life". Dictionaryof Human Geography (5th Ed.). Oxford: WileyBlackwell. ISBN978-1-4051-3287-9.

Hofstede, G. (1997). Cultures and organizations: Software of the mind. New York: McGraw Hill.

Hofstede, G. (1980). Culture's consequences: International differences in work related values. Beverly Hills: Sage.

Kahneman, D.; Deaton, A. (2010). "High income improves evaluation of life but not emotional well-being". Proceedings of the NationalAcademy of Sciences 107 (38)

Lane, H., DiStefano, J. \&Maznevski, M. 2006, International management behavior: text, readings and cases, 5 . edition edn, Blackwell, Oxford.

Layard, Richard (6 April 2006). Happiness: Lessons from a NewScience. London: Penguin. ISBN 978-0-14-101690-0.

Matthews, Gerald; Deary, Ian J.; Whiteman, Martha C. (2003). Personality Traits (2nd Ed.). Cambridge University Press. ISBN 9780521831079.

Martha Nussbaum and Amartya Sen, ed. (1993). The Quality of Life,Oxford: Clarendon Press. Description and chapter-preview links.

Morris, Morris David (January 1980). "The Physical Quality of LifeIndex (PQLI)". Development Digest 1: 95-109.

Ng, Y. \&Earley, C. 2006, "Culture + Intelligence: old constructs, new frontiers", Group \& Organization Management, vol. 31, no. 1, pp. 4.

Trompenaars, F., \& Hampden-Turner, C. (1997). Riding the waves of culture: Understanding cultural diversity in business (2nd Ed.). London: Nicholas Brealey Publishing.

Sternberg, R. J., \&Detterman, D. (1986). What is intelligence: Contemporary viewpoints on its nature and definition. Norwood: Ablex. 